\title{
An Investigation of Oral Interaction in English as a Foreign Language Classroom
}

\author{
Norah Ibrahim Almohizea \\ College of Languages \& Translation, King Saud University, Riyadh, Saudi Arabia
}

Email address:

nalmohizea@ksu.edu.sa

\section{To cite this article:}

Norah Ibrahim Almohizea. An Investigation of Oral Interaction in English as a Foreign Language Classroom. International Journal of Language and Linguistics. Vol. 6, No. 3, 2018, pp. 51-60. doi: 10.11648/j.ij11.20180603.11

Received: March 16, 2018; Accepted: April 11, 2018; Published: May 21, 2018

\begin{abstract}
This thesis presents the findings of a study into classroom oral interaction in an EFL class in Saudi Arabia. One teacher was observed while teaching at an EFL private institution in Saudi Arabia. The purpose of the study was four-fold: to determine the amount of the L1 (native language) and the TL (target language) used in the classroom; to compare the teacher's contribution in class with students' contributions; to identify the interactional moves the teacher used to elicit students' participation and to analyse the teacher's corrective feedback and its effectiveness. The findings indicated that even though the teacher used the TL extensively, students' contributions were scarce. The findings also suggest that students' contributions were influenced by the teacher's elicitation techniques. Finally, the analysis of the teacher's corrective feedback revealed that it did little to improve students' acquisition of the TL.
\end{abstract}

Keywords: Corrective Feedback, Elicitation Techniques, Oral Interaction, Students' Contributions, Teacher's Contribution

\section{Introduction}

One of the most controversial issues in EFL (English as a foreign language) studies is the use of the native language in the foreign language classroom. Many studies suggest that using the TL (target language) only is the only way for students at an EFL context to practice the TL [1]. For decades, teachers have avoided the use of the L1 (native language) in the classroom believing that it is for the students' best interests [2]. In many classrooms teachers try to maximize the use of the TL in order to expose their students to the TL. The research in this field has focused largely on the amount of the L1 or the TL teachers use in ESL classrooms. Many studies also investigated the functions teachers assign to the L1 or to the TL (e.g. [3-5]). These studies, however, neglect students' responses to the teachers' use of the TL The present study will look into students' contributions as opposed to the teacher's contribution. This is extremely important as it is the only way that determines the effect of the teacher's use of the TL in the classroom.

The study will also investigate how the teacher elicits students' participation in class. The aim of this investigation is determining the effect of the teacher's eliciting techniques on students' contribution in class. Much of the research to date has found that different interactional moves yield different results [6]. Thus, the current study will examine the teacher's interactional moves in order to determine if it is related to students' participation behavior.

Finally, the present study will examine how the teacher gives corrective feedback.

The existing research on corrective feedback has focused largely on determining which types of feedback are the most effective at improving student acquisition of the TL and how students respond to feedback (uptake). The form of feedback given (i.e., positive or corrective) and its effects on accuracy of student have also been widely investigated. Similar to the previous studies the aim of the current study is determining the effect of teachers' feedback on students' uptake and contributions in class.

\section{Literature Review}

This chapter discusses issues and research related to teacher talk. It begins with the issue of the use of the L1 and summarizes studies that investigated teachers' use of L1 and $\mathrm{TL}$ in the L2 classroom. It then considers certain key functions of teacher talk: namely the techniques teachers use to elicit participation in the classroom and the provision of 
corrective feedback.

\section{1. $T L$ vs. $L 1$}

Despite teachers' best intentions to avoid the use of the L1 in the classroom, the L1 is always present. Studies show that the majority of teachers use the L1 to varying extent and for various purposes (e.g. [3, 7, 5]). Some use it extensively while others use it sparingly [7]. For instance, Edstrom conducted a case study where she observed herself [2]. She recorded herself during her L2 Spanish classes over the period of one semester. She also kept a journal where she wrote her perceptions about her use of the L1 in her classes. The amount of English or Spanish used in each class was measured using a stop watch. One of the most intriguing findings of her observation is that she was unaware of how much she used the L1 in her classes. She notes that as a linguist and a good teacher she thought that the L1 should be abandoned in class. The data analysis revealed that despite her conviction that she should maximize the use of the TL, she used the L1 on a regular basis. Edstrom found that she used the L1 to explain difficult concepts, to give grammatical instructions and for classroom management.

White conducted a longitudinal study where she also investigated teachers' use of the L1 in two French foreign language classes at two Australian universities [3]. Classes of two teachers, one native speaker of French and one nonnative speaker, were observed and audio recorded over a twelve-week semester. White was interested in the amount of L1 used in each class, the functions that L1 serve and teachers' and students' attitudes towards L1 use. The researcher found that the NNS teacher used more L1 than the NS teacher as the NNS teacher used the L1 in half of the teacher-talk turns. White reports that the difference between the NNs teacher and the NS teacher in the amount of the L1 used was not related to the teacher's status but rather to their personal opinion which the teachers expressed in the interviews. White found that the most common uses of the L1 in the classroom were translation and vocabulary explanations.

Another study that investigated teachers' language choices in foreign language (FL) classroom was by Kim and Elder [7]. They investigated language choices made by native speaker teachers of Japanese, Korean, German and French in FL classrooms in New Zealand. The researchers examined the use of English which was the lingua franca in all classrooms compared to the use of the TL, and the pedagogical functions that the languages used served. Kim and Elder reported that despite the fact that all teachers were native speakers of the TL, the amount of TL used in each classroom varied greatly. The amount of the TL used by one teacher was $88 \%$ compared to only $23 \%$ used by another teacher. The study found that teachers also varied in the role they assign to the TL. However, the researchers reported that most of the teachers restricted their use of the TL to interactions that are linguistically less complicated.

According to Paker and Karaagac teachers should not feel guilty about using L1 in the classroom [5]. The study was conducted in the School of Foreign Languages at Pamukkale University. Data were collected through class recordings, questionairs, and interviews of teachers and some students. They found that although teachers and students were aware of the importance of maximizing the use of TL, L1 was used in the classroom. Teachers and students were also aware of the amount of L1 used in the class. He found the teachers used L1 to communicate with students, to clarify and to explain difficult concepts and ideas.

Unlike studies focusing on the amount and functions of teachers' use of L1 or TL, the study by Critchon investigated teachers' use of the TL and how students responded to their teachers' extensive use of the TL [8]. Five modern language teachers-four French teachers and one German teacher-at a Scottish secondary school were observed and audio recorded for several weeks while teaching their classes.

Critchon reports that teachers used many strategies that allowed them to maximize the use of the TL while keeping their students' interest. For instance, one teacher encouraged students to use the TL by asking students to have a conversation at the beginning of each class. Even though students often used fixed utterances, this routine encouraged students to use the TL. Critchon also found that teachers tried to maintain their students' interest by asking them repeatedly about their comprehension. The study also found that teachers adjusted their language according to their students' level. The study found that teachers' use of the TL encouraged students to use it in the classroom. Critchon believes that by using the TL effectively in class, students will have better confidence to use the TL outside the classroom.

Varshney and Rolin-lanziti investigated students' perception of the use of the TL in language classroom in a context where the use of the TL was maximized [4]. Fiftytwo learners of French in Queensland University were included in this study. At this particular university the use of the L1 was discouraged by teachers and administration. When teachers were carefully observed, it was found that they indeed rarely used the L1 in the classroom. Data were collected using a questionnaire that asked students about their perception of the importance of the L1 and the TL. The researchers reported that in general students had a negative attitude towards the use of L1 in the classroom. Students pointed out that although the use of the L1 might decrease their anxiety, they believed that it was demotivating. Similar to Critchon's suggestion, students indicated that in order to learn the TL it should be used as often as possible [8]. Students, however, indicated that the L1 could be more effective in classroom management.

As can be seen in the above studies, there is an ongoing debate regarding the use of the L1 in the classroom. For years, there has been an ongoing interest on the pros and cons of using the L1 in FL classroom. Some studies attempted to investigate the amount of L1 and L2 teachers use [7] and[3], while some studies investigated students' perception of the teachers' use of TL [4]. However, few addressed the issue of how teachers use of the TL affects students' use of the TL in 
the classroom [8].

\subsection{Elicitation}

An important aspect in classroom interaction is the way in which the teachers elicit students' participation in class. This is extremely important as the elicitation method would determine students' response which could promote language learning. However little research has been conducted on the way in which teachers elicit participation. A smaller body of research has been conducted in an EFL setting.

Brulhart compared speech used by ESL teachers while teaching beginners and advanced learners of English [9]. Four ESL teachers with at least 5-years teaching experience participated in the study. The participating students were all enrolled at a community college ESL program and they were from different L1. The study investigated the frequency of nine interactional moves. These moves include: or-choice questions, referential questions, display questions, expansions, self-repetitions, other-repetitions, comprehension checks, confirmation checks and clarification requests. Orchoice questions are when the teacher asks a question that has two possible answers. Referential questions ask for answers that are not known by the teacher. When a teacher asks a display question, the answer to the question is known by the teacher. Expansions are when the teacher repeats his or the student's utterance and provides explanations about grammatical functions. Self-repetitions are when the teacher repeats part or all of his utterance. Other-repetitions happen when the teacher repeats the student's utterance. Comprehension checks are given when the teacher tries to confirm that his utterance was understood by the students. In Confirmation checks the teacher asks for confirmation that the student's utterance was understood. In clarification requests the teacher indicates that the student's utterance was not understood and hence asks for clarification. The study found a large number of self-repetitions and display questions while or- questions and clarification requests were rarely used by all teachers. The study found that different interactional moves were used differently based on students' proficiency level: self-repetitions and display questions were used more often with beginners while referential questions were used more with advanced learners. Expansions, otherrepetitions, comprehension and confirmation checks were not affected by students' proficiency level. The study found that interactional moves were affected by the content of the lesson, the teaching style of each teacher as well as students' proficiency level.

Shomoossi conducted classroom research in forty reading comprehension classes at two universities in Teheran [6]. The researcher investigated the effect of teachers' questioning behavior on EFL classroom interaction. Five university teachers were observed during a two-month period. Unlike Brulhart's study which investigated many interactional moves, Shomoossi's investigation was on teachers' use of two interactional moves only: referential and display questions [9] and [6]. Similar to Brulhart's study, Shomoossi found that the number of display questions was higher than referential questions [9] and [6]. The study found that when teachers asked display questions they did not usually give sufficient time for students to answer. Interestingly, Shomoossi also found that display questions were asked for textbook information while referential questions were used for personal information or for general topics such as education, crimes and politics. By measuring the amount of classroom interaction in minutes, the study found that referential questions resulted in longer classroom interaction and were usually used at the beginning of each lesson to familiarize students with the new topic while display questions were used while working on exercises. Shamossi also identified a new type of questions (general questions) which are not addressed to any student and to which students respond silently or as a group.

Alsubaie investigated the techniques that teachers use to elicit participation in the classroom [10]. Data were collected from recordings of three different English language classes at King AbdulAziz University. Data were analyzed using conversational analysis. The results indicated that teachers used three techniques to elicit students' participation in the classroom: Yes/No questions, closed/display questions and open referential questions. Yes/No questions were used quite more often than the other two. However, open referential questions resulted in longer oral interaction. The study found that the use of a certain type over another was influenced by the teacher's pedagogical purpose.

\subsection{Teachers' Corrective Feedback}

Feedback is an issue that has attracted a lot of attention in SLA. The main debate concerns the use of either corrective (correcting students' mistakes) or positive (confirming what students said) feedback. Advocates of corrective feedback (e.g. S: newspapers; T: and in newspapers) argue that it is more effective than positive feedback (e.g. S: advertisement; T: it's advertisement yes) for classroom interaction as it helps students attain a native -like level of accuracy as well as encouraging them to negotiate for meaning [11] and [12].

A number of studies investigated the effect of different types of feedback on learners' uptake. The aim of these studies was finding which type of feedback would result in students' uptake as well as improving students' accuracy. For example, Lyster and Ranta investigated corrective feedback and learners' uptake in four immersion classrooms in Montreal [12]. Uptake is defined by the researchers as the student's utterance that immediately follows feedback and that constitutes a reaction to the teacher's feedback. They identified six different types of corrective feedback: explicit correction, recasts, clarification requests, meta-linguistic feedback, elicitation and repetition. Lyster and Ranta defined explicit correction as "the explicit provision of the correct form" (p.46) [12]. They defined recasts as "teacher's reformulation of all or part of a student's utterance, minus the error" (p.46). Following Spada's and Frohlich's, they defined clarification requests as "the teacher's indication to students that their utterance has been misunderstood or that the utterance is ill-formed in some way that reformulation or 
repetition is required" (p.47) [13]. Meta-linguistic feedback contains comments, information or questions related to the well-formedness of the students' utterance without explicitly providing the correct form (p.47). In elicitation, teachers use different techniques such as asking for a completion of an utterance, demanding reformulation or asking questions to elicit correct forms(p.48). Repetition refers to the teacher's repetition, in isolation, to the students' erroneous utterance (p.48).

Kirgoz \& Agcam, investigated teachers' perceptions about different types of corrective feedback [14]. Thirty six EFL teachers at 20 different state primary schools in Adana were interview to find out their opinions about corrective feedback and its different types. The study found that teachers believed that students mistakes should be corrected. Half of the participants believed that feedback should be given immediately while $30 \%$ thought it should be delayed. Moreover, half of the participants believed that the feedback should be given by the teachers while 33\% thought students should correct their own mistakes. On the other hand, some teachers stated that a teacher should give feedback when the student is not able to correct the mistake on his own. $22 \%$ teachers thought all types of mistakes should be corrected while others suggested that only mistakes of formation and phonological errors should be corrected. Results indicated that explicit correction, recasts and repetition were the most common form of feedback. Nevertheless, elicitation was the most effective form of feedback in EFL classroom.

Lyster and Ranta found that recasts were the most common form of feedback used by the teachers [12]. However, the researchers reported that recasts were the least likely form of feedback that would lead to students' uptake while elicitation was always successful in generating uptake. Lyster and Ranta believe that students' uptake is extremely important as it allows students to use their knowledge of the TL in order to deal with the error which would eventually result in language development.

Long, Inagaki, and Ortega conducted two laboratory studies that investigated the effect of recasts (implicit negative feedback), models (positive input) and zero feedback on the acquisition of certain problematic grammatical features [11]. Two groups were included in the study: Japanese and a Spanish group. The study investigated Japanese students' acquisition of adjective ordering and fronted locative constructions. The Spanish students were tested for their acquisition of object topicalization and adverb placement. The two groups (Japanese and Spanish) were divided into three groups: two treatment groups and a control group. Participants in the first treatment group listened to models of the target structures while participants in the second treatment group listened to recasts of the target structures. Using a pre-test, posttest, control group design gain scores were compared. Gain scores revealed that there was no significant difference between the Japanese control and experimental groups or between the experimental groups. The researchers found that recasts were more effective than models in Spanish students' acquisition of adverb placement.
However, there was no significant difference between the Spanish groups in the object topicalization. Long, Inagaki, and Ortega concluded that implicit negative feedback (recasts) is more effective than positive input(models) for the acquisition of certain L2 structures.

Lyster and Saito investigated the effectiveness of oral feedback using a meta-analysis whereby they gathered and weighed available evidence offered by results from all primary studies addressing a common research problem [15]. Based on 15 classroom-based studies the researchers found that corrective feedback has a significant durable effect on learning of the TL. They also found that the type of feedback has an effect on TL development. Unlike other previous studies [11] and [12]. Lyster and Saito found that prompts are more effective than recasts in TL development. The study found that feedback was influenced by the type of response that is expected from learners. They found that students who were asked to produce the language with little or no constraint benefitted more from the feedback than students who were forced to use the TL or those who were asked to choose a certain answer or to judge the grammaticality of a certain TL structure. Lyster and Saito found that feedback was not influenced by the difference in instructional settings: FL (foreign language) vs. SL (second language).

Ammar and Spada investigated the effectiveness of two kinds of corrective feedback (recasts and prompts) on learners of different proficiency level [16]. Sixty-four students taking intensive ESL classes participated in this study. Students were divided into three groups. The first group received corrective feedback in the form of recasts. The second group received corrective feedback in the form of prompts. The last group was a control group who only received exposure to instructions and input. The researchers investigated students' acquisition of the third-person possessive determiners (his and her) over a 4-week period. Students' knowledge of that particular feature was tested right before the experiment and immediately after it was conducted and again four weeks after the experiment. The study found that the two experimental groups benefited from the corrective feedback. Ammar and Spada found that the effectiveness of feedback is determined by students' proficiency level. Similar to Lyster's and Saito's study they found that while high proficiency students benefited equally from both forms, prompts were far more effective than recasts in low proficiency learners [15].

The issue of how FL teachers give corrective feedback has largely focused on determining which types of feedback are the most effective in encouraging students' uptake. Many studies investigated the effectiveness of different types of feedback on students' uptake. Recasts were the most common type of feedback used by teachers in many classes. However, the effectiveness of recasts was influenced by different contexts and different proficiency levels.

\subsection{Research in the Gulf Countries}

As the previous literature clearly shows there were no studies conducted in Saudi Arabia on the issues discussed. 
The lack of research is not restricted to Saudi Arabia but it is also the case in most of the Gulf regions. Syed investigated the challenges that face EFL teachers in the Gulf regions. The first challenge that faces teachers in the gulf region is the unprecedented development in education in the gulf region [17]. Syed believes that the fact that this development happened in a very short time makes it hard for the teachers to adapt to it. Syed reported that most of the EFL teachers are expatriates who are in need of teacher education programs. He also found that the current approaches are not suitable for the uniqueness of the Gulf region and hence need to be modified. Syed stated that the last challenge that faces EFL teachers and which might affect the development of the education system is the lack of research. Syed believes that in order to develop and design the educational system, more research that shed light on the education situation should be conducted.

In summing up this chapter, we can conclude that while many studies investigated teachers' use of the L1 and the TL in the classroom, few addressed students' response to teachers' use of the L1 or the TL. A closer look into studies regarding elicitation techniques reveals that little research was conducted in that area and although few were conducted in the Western countries none were conducted in nonWestern countries. Furthermore, even though feedback was thoroughly investigated in the western countries, no studies were conducted in non-western countries such as Saudi Arabia.

\subsection{Research Questions}

The aim of the present study was to investigate teacher talk (and student responses) in Saudi EFL classes. Using a case study approach (one teacher teaching a number of EFL classes), the study set out to investigate the following:

1) What is the amount of the L1 and the TL used by a teacher and students in an EFL class in Saudi Arabia?

2) Does the teacher's use of the TL result in students' use of the TL?

3) What interactional moves does a teacher in Saudi Arabia use to elicit students' participation?

4) How does a teacher in Saudi Arabia give corrective feedback?

\section{The Study}

This chapter provides details about the study. It describes the educational context in which the study took place and provides background information about the participants. It then describes the data collection procedure, as well as data analysis and coding system.

\subsection{Educational Context}

The study was conducted in a private EFL institution in Saudi Arabia. The institution offers a two-year English diploma program. The aim of the program (www.alfac.edu.sa) is to enable students to perform effectively in an English speaking environment. The minimum requirement for enrolment in this program is a high school certificate. At the beginning of the program students take a placement exam and are placed at the appropriate level that is compatible with their proficiency level. Each month students finish a different level ( 80 hours). Upon completion of the eleventh level students receive a diploma in English certified by the Saudi Ministry of Education.

EFL classes at the institution are offered four times per week. Each class session is around 35-45-minute long. The classes focus on different language skills. Most of the classes are devoted to developing reading skills as well as vocabulary and grammar. The class size is approximately 1520 students. Even though there is no written policy that prohibits the use of the L1 (Arabic), teachers are encouraged to avoid using L1 as much as possible as it is taken as an indication of the teacher's incompetence in the TL.

Data were collected from a level two (it includes students at the second semester of their study) EFL class taught by the same teacher. The participating teacher (male) is an experienced teacher who has been teaching EFL classes for over fifteen years. The teacher was not aware of the exact purpose of the data collection in order to maintain a natural setting as much as possible.

Prior to the study, ethical consent was sought from the University of Melbourne and from the private institution in Saudi Arabia. Written consent was also sought from the participating teacher prior to the data collection. (see Appendix A)

\subsection{Data Collection}

The participating teacher was audio-recorded during eight class sessions. The recordings were conducted over a period of 4 weeks. Two recordings were excluded due to the poor audio quality. Each class had a different Language focus: vocabulary, reading, and grammar (Table 1). The teacher wore a radio microphone which also captured most of the students' oral interaction. This was a relatively effective method to capture most of the oral interaction that took place in the classroom. Video recording might have been more effective as it would capture the facial expressions and the body language but such procedure would require resources as well as consent from participants who would probably disagree considering the uniqueness of the Saudi culture.

Table 1. Time and focus of classes.

\begin{tabular}{|c|c|c|c|c|c|c|}
\hline & Class 1 & Class 2 & Class 3 & Class 4 & Class 5 & Class 6 \\
\hline Date class recorded & $25 / 9$ & $26 / 9$ & $9 / 10$ & $10 / 10$ & $11 / 10$ & $12 / 10$ \\
\hline Focus of the class & Introduction Vocabulary & Vocabulary Reading & Reading & Reading & Reading Skimming scanning & Grammar \\
\hline
\end{tabular}

Data Analysis 
All the recordings were transcribed and coded. The data were then analysed for the teacher's and students' contribution (noting whether it was in L1 or L2). All teacher talk was then coded for instances of feedback and elicitation. In order to check for inter-rater reliability, one complete lesson transcript was coded by another researcher. Inter-rater reliability (the percentage of similar codings of all codings) was $86 \%$. (see Appendix B)

\subsection{Teacher's vs. Students' Contribution in Class}

The data were first analysed for the amount of teacher's contribution in class as opposed to students' contribution. This was established by counting the number of words produced by each. The number of L1 words was also counted and included in the tally of contributions.

\subsection{Teacher's Elicitation Strategies}

The data were also coded for the strategies the teacher used to elicit students' participation. All instances of elicitation were identified and counted. In some turns, the teacher repeated or rephrased the elicitation a number of times. Repeated elicitations which occurred in the same turn were counted only once. The data were then coded and classified according the elicitation strategy the teacher used. There were mainly three types of elicitations that the teacher used: questions, invitations, commands and recaps.

There were a number of questions that were clearly rhetorical rather than a means of eliciting students' participation and these were not coded as elicitations.

$$
\text { E.g. }
$$

$\begin{array}{ccl}42 & \mathrm{~T} & \begin{array}{l}\text { When we advertise what goal what } \\ \text { objective do we have in mind? }\end{array} \\ 43 & \mathrm{~T} & \begin{array}{l}\text { Why do we advertise? } \\ \text { Again as I said you start a business you } \\ \text { advertise you start your business }\end{array}\end{array}$

The questions that expected an answer were coded and classified according to the type of answer expected. The first type was when one word was expected, as in Yes/No

E.g.

$78 \mathrm{~T}$

So sometimes next day you buy that

$79 \mathrm{~S} \quad$ No $\quad$ always buy things you watch on TV

or True/False type questions:

E.g.

$\begin{array}{lll}140 & \mathrm{~T} & \begin{array}{l}\text { company must translate its } \\ \text { advertisement true or false }\end{array} \\ 141 & \mathrm{~S} & \text { False }\end{array}$

The other type of questions were those where a longer answer was expected.

E.g.
$10 \mathrm{~T}$
Now advertisements are everywhere where can
11 S1 you see advertisements?
12 S2 In TV

The last category is for questions that expect detailed information.

E.g.
$87 \mathrm{~T}$
What should we think about when we plan advertising campaign?
$89 \mathrm{~S}$ The important thing is to make my product the best of any

In invitations the teacher doesn't ask for an answer directly from a certain student but invites students who may have the answer to participate.

E.g. T With a commercial. Ok. I mentioned some medium where we advertise. What are these again - who may name them?

Commands are when the teacher directly tells the student to participate.

E.g. T Ok. The third one, read it please?

Recaps are when the teacher tries to elicit an answer by mentioning something that was discussed earlier in other lessons.

E.g. T False so it is not enough to translate can you tell us for example what else we need in addition to the language so translating an advertisement into another language is not enough what else do we need?

\subsection{Teacher's Feedback}

The teacher provided feedback on the students' language use as well as on content (e.g. responses to comprehension questions in reading). Since the focus of this study was on language use, I coded and counted only instances where the teacher commented on students' use of language.

Based on the work of Lyster and Ranta, feedback was coded and classified into four categories according to their type: repetitions, recasts, explicit corrections and questions [12]. According to Lyster and Ranta recasts are "teacher's reformulation of all or part of a student's utterance, minus the error" (p.46). In explicit feedback the teacher provides correction by stating where the mistake is. In contrast, when implicit feedback is used, feedback is given indirectly using elicitation, repetition, metalinguistic clues and clarification requests to enable students to correct their mistakes by themselves.

The following excerpts from the data illustrate the four types of feedback.

Excerpt 1 provides an example of repetition where the teacher merely repeats student's words with further elaboration (underlined in the transcript).

Excerpt 1:
4 S The world of advertising
$5 \mathrm{~T}$ The world of advertising the world of advertising this is the title of the first unit [lecture one] 
Excerpt 2 provides an example of a recast where the teacher repeated the student's words minus the error for which he provides a correction (underlined in the transcript).

Excerpt 2:

$18 \mathrm{~T}$ Where else

$19 \mathrm{~S}$ In the radio

... on TV in newspapers and magazines so for

$20 \mathrm{~T}$ business of course we need advertisements [lecture one]

In excerpt 3 the teacher provides feedback in an explicit manner. He directly states the student's mistake.

Excerpt 3

79 S I want go to university.

$80 \mathrm{~T}$ Listen to her sentence: I want go to university. Is

$\mathrm{T}$ this sentence correct?

81 T No.

What do we need? Can you correct it please? Thank you. So 'I want to go', so this verb cannot be used

$82 \mathrm{~T}$ with another verb without 'to', it is followed by an affinitive with 'to'. So here, as you see, this 'to' is very important with that verb. So I want to go to, so I want to use, to express ability. [lecture 15]

In excerpt 4 , the teacher provides feedback using a question.

Excerpt 4:

112 S could

$113 \mathrm{~T}$ Why could here? Because we have the past. [lecture 15]

\section{Results}

This chapter summarizes the results of data analysis. It starts with a brief summary of the findings of the amount of L1 used by both the teacher and students. It also presents the findings of students' and teachers' oral contribution in class. The teacher's contributions are presented in terms of overall talk, feedback, and elicitations techniques.

\section{1. $L 1$ vs. $L 2$}

Table 2 shows the amount of L1 used by the teacher and students in each class. L1 was used in the first two classes only. In the first class the teacher used ten words in L1 while the L1 was never used by students in that class. In the second class the amount of L1 used by the teacher decreased to six words while there were two words in the L1 used by students. The total amount of L1 used by both the teacher and students is 18 . This means that out of the total number of words (18153) there were only 18 words in L1.

Table 2. The amount of L1 (in words) used by the teacher and students in each lecture.

\begin{tabular}{llllllll}
\hline Lecture & $\mathbf{1}$ & $\mathbf{2}$ & $\mathbf{3}$ & $\mathbf{4}$ & $\mathbf{5}$ & $\mathbf{6}$ & Total \\
\hline L1 by teacher & 10 & 6 & 0 & 0 & 0 & 0 & 16 \\
L1 by students & 0 & 2 & 0 & 0 & 0 & 0 & 2 \\
Total & 10 & 8 & 0 & 0 & 0 & 0 & 18 \\
\hline
\end{tabular}

\subsection{Teacher's vs. Students' Contribution in Class}

An analysis of the class oral interaction reveals that the majority of classes were teacher-oriented. The number of words produced by the teacher was computed and compared to the number of words produced by students in each class. Table 3 shows the number of words produced by the teacher compared to the number of words produced by students expressed as a percentage of the total class talk. In almost all classes the average talk by the teacher was $95 \%$ of the total amount of talk. Students contributed only $5 \%$ of the total amount of talk in all classes.

Table 3. Teacher vs. students' contributions to class talk (in percentages).

\begin{tabular}{lllllll}
\hline Lecture & $\mathbf{1}$ & $\mathbf{2}$ & $\mathbf{3}$ & $\mathbf{4}$ & $\mathbf{5}$ & $\mathbf{6}$ \\
\hline Teacher & $94 \%$ & $93 \%$ & $96 \%$ & $92 \%$ & $96 \%$ & $96 \%$ \\
Students & $6 \%$ & $7 \%$ & $4 \%$ & $8 \%$ & $4 \%$ & $4 \%$ \\
\hline
\end{tabular}

A closer look at the classes' oral interaction reveals that students' contribution was mainly 1-2 word turns (see Excerpt 4 below). These 1-2 word turns were usually in response to a teacher question. Such questions (see subsequent results) often required from students a true or false or simply Yes or No response. Table 4 shows the total number of turns produced by students in each lecture, and the number of 1-2 word turns. As the table shows, in most lectures, approximately $50 \%$ of students' turns were 1-2 word turns.

Table 4. Students turns in each lecture and the number of 1-2 word turns.

\begin{tabular}{llllllll}
\hline Lecture & $\mathbf{1}$ & $\mathbf{2}$ & $\mathbf{3}$ & $\mathbf{4}$ & $\mathbf{5}$ & $\mathbf{6}$ & total \\
\hline Students' turns & 53 & 72 & 29 & 55 & 50 & 48 & 307 \\
$\begin{array}{l}\text { Students' 1-2 word turns } \\
\begin{array}{l}\text { Students 1-2 word turns } \\
\text { as \% of total turns }\end{array}\end{array}$ & 27 & 53 & 9 & 29 & 21 & 16 & 155 \\
\hline
\end{tabular}

Excerpt 4, taken from Lecture 2, shows an example of a 12-word turn.

Excerpt 4:

$73 \mathrm{~T} \quad \ldots$ another word that starts with 'p'?

74 S To persuade.

Interestingly, when we look closely at the data we find that when the turns are longer than 1-2 words they are grammatically incorrect (see Excerpt 5). Longer students' responses that were grammatically correct were instances where the students were merely reading from the book (see Excerpt 6).

Excerpts 5 (from Lecture 6) and 6 (from Lecture 2) show examples of students' longer turns.

Excerpt 5:

79 S I want go to university.

Excerpt 6:

$160 \mathrm{~T} \quad \ldots$ The last sentence, connect it with this one?

161 S If they fail, they will need to rethink their ideas and develop a better plan. 


\subsection{Elicitation}

Table 5 shows the number of elicitation instances in each lecture and of those, elicitation instances where the expected answer is one to two words. The table shows that the teacher expected a 1-2 word response in $40 \%$ of the elicitation instances.

Table 5. Total elicitation instances and 1-2 word elicitation instances in each lecture.

\begin{tabular}{llllllll}
\hline & $\mathbf{1}$ & $\mathbf{2}$ & $\mathbf{3}$ & $\mathbf{4}$ & $\mathbf{5}$ & $\mathbf{6}$ & Total \\
\hline Elicitation instances & 49 & 106 & 25 & 49 & 71 & 57 & 375 \\
1-2 word elicitation instances & 27 & 50 & 9 & 21 & 23 & 16 & 146 \\
$\begin{array}{l}\text { \% of 1-2 word elicitation } \\
\text { instances }\end{array}$ & $55 \%$ & $47 \%$ & $36 \%$ & $43 \%$ & $32 \%$ & $28 \%$ & $39 \%$ \\
\hline
\end{tabular}

Table 6 summarizes the type and number of elicitation techniques the teacher used in each lecture. As the table shows the most common technique of elicitation is questions. The teacher also uses invitations quite frequently. Commands and recaps are less common and are not used in each class.

Table 6. Type and number of elicitation techniques in each lecture.

\begin{tabular}{llllllll}
\hline Lecture & $\mathbf{1}$ & $\mathbf{2}$ & $\mathbf{3}$ & $\mathbf{4}$ & $\mathbf{5}$ & $\mathbf{6}$ & Totals \\
\hline Question & 39 & 24 & 14 & 32 & 49 & 22 & 180 \\
Invitation & 5 & 32 & 11 & 13 & 21 & 17 & 99 \\
Command & 3 & 3 & 0 & 2 & 1 & 0 & 9 \\
Recap & 2 & 2 & 0 & 2 & 2 & 1 & 9 \\
Totals & 49 & 61 & 25 & 49 & 73 & 40 & 297 \\
\hline
\end{tabular}

\subsection{Teacher's Feedback}

Table 7 below summarizes the number and the type of feedback in each lecture. The amount of feedback in each lecture is computed by the number of instances in which feedback is given. The type of feedback is classified into either feedback on content or language. Feedback on language includes feedback on vocabulary and grammar, noting also whether it was positive (confirming what the students said) or corrective. Feedback on content deals with feedback on the content of the text book or topic discussed. As Table 7 shows the majority of feedback turns are on content rather than language. The only exception is the last lecture which focused on language since it was a grammar class. As for positive and corrective feedback, Table 8 shows that positive feedback was used sparingly. Corrective feedback was used more often but overall was given sparingly as well.

Table 7. Number and type (language vs. content) of instances of Teacher's feedback in each lecture.

\begin{tabular}{llllllll}
\hline Lecture & $\mathbf{1}$ & $\mathbf{2}$ & $\mathbf{3}$ & $\mathbf{4}$ & $\mathbf{5}$ & $\mathbf{6}$ & Total \\
\hline Feedback on content & 20 & 56 & 21 & 28 & 45 & 1 & 171 \\
Feedback on language & 14 & 1 & 3 & 6 & 5 & 33 & 62 \\
Instances of feedback & 34 & 57 & 24 & 34 & 50 & 34 & 233 \\
\hline
\end{tabular}

Table 8. Type (positive vs. corrective) of Teacher's feedback in each lecture.

\begin{tabular}{llllllll}
\hline Lecture & $\mathbf{1}$ & $\mathbf{2}$ & $\mathbf{3}$ & $\mathbf{4}$ & $\mathbf{5}$ & $\mathbf{6}$ & Total \\
\hline Positive feedback & 2 & 1 & 1 & 1 & 1 & 0 & 6 \\
Corrective feedback & 12 & 1 & 1 & 6 & 7 & 14 & 41 \\
Total & 14 & 2 & 2 & 7 & 8 & 14 & 47 \\
\hline
\end{tabular}

Table 9 summarizes the techniques used to give feedback in each class. As the table shows the most common technique the teacher used is repetition. Recasts come second followed by explicit correction and questions.

Table 9. Feedback techniques in each lecture.

\begin{tabular}{llllllll}
\hline Lecture Feedback & $\mathbf{1}$ & $\mathbf{2}$ & $\mathbf{3}$ & $\mathbf{4}$ & $\mathbf{5}$ & $\mathbf{6}$ & Totals \\
\hline Repetition & 3 & 14 & 16 & 27 & 39 & 26 & 125 \\
Recast & 6 & 1 & 3 & 6 & 3 & 0 & 19 \\
Explicit correction & 4 & 1 & 1 & 4 & 4 & 4 & 21 \\
Question & 1 & 1 & 1 & 1 & 4 & 9 & 17 \\
\hline
\end{tabular}

Excerpt 7 and 8 show examples of the teacher's feedback. In Excerpt 7 the teacher offers feedback on vocabulary by asking a question and then elaborating on the meaning of the vocabulary item. Excerpt 8 shows an example of teacher's feedback on grammar. In this example the teacher uses a question for feedback. It is worth noting that in both examples students were not given a chance to uptake the feedback. The teacher rapidly moves to another point. A closer look into the data reveals that students are rarely given the chance to uptake the teacher's feedback. It may also not always be very clear to the students whether the feedback is positive or corrective.

Excerpt 7:

$103 \mathrm{~T}$... what do we call this person?

104 S The cooker.

Cooker. Cooker is the stove, the machine. What do we call the

$105 \mathrm{~T}$ person who cooks? Cooker. Cooker is the stove, the machine. What do we call the person who cooks?

$106 \mathrm{~T}$ In addition to this, let's have another drill...

[Lecture 1]

Excerpt 8:
112 S Could
$113 \mathrm{~T}$ Why 'could' here again?...next sentence?

[Lecture 6]

\section{Discussion}

Maximizing the use of the TL in the classroom is one of the most important aims in foreign language classrooms. Teachers avoid the use of the L1 in order to expose learners to the TL. Many studies have addressed the amount of the TL teachers use in the classroom as well as the functions teachers assign to the L1 [7]. Similarly, other studies addressed the amount of the L1 as well as the functions teachers assign to the L1in the classroom [2]. The present study investigates the possible impact of teachers' maximized use of the TL on students by comparing the teacher's contribution in class compared to students' contributions. The study also focuses on the strategies the teacher uses to elicit students' contribution. Feedback strategies are also taken into consideration to determine the possible impact of the teacher's feedback on students' contributions in class. This 
chapter presents a detailed discussion of each of the research questions.

\subsection{Amount of L1 Used by the Teacher and Students}

Both the teacher and students used a fairly little amount of L1 and it was only in the first two lectures. The total amount of L1 used by both the teacher and students is 18 out of the total number of words (18153).

The amount of L1 used in classes in this study was less than the amount of L1 used in similar studies that investigated the use of L1 in TL classes and reported a varied use of the L1 (ranging from $22 \%$ to $77 \%$ ) [7]. The teacher in this study apparently avoided the use of the L1 in his classes. The teacher was probably following the long held belief that maximizing the use of the TL was in students' best interests (Turnbull\& Arnett, 2002). Following the teacher's example, students also rarely used the L1 in classroom interaction. The most important issue, though, is whether teacher's avoiding the use of the L1 would result in improving students' acquisition of the TL. This is a question that needs to be investigated in future studies.

\subsection{The Effect of the Teacher's Use of the TL on Students' Use of the TL}

The teacher was successful in maximizing the use of the $\mathrm{TL}$ in the classroom (he only used 16 words in L1 and only in the two first lectures). However, in most of the classes the teacher was the major contributor in the class oral interaction (the average talk by the teacher was $95 \%$ of the total amount of talk. Students contributions were limited $(5 \%$ of the total amount of talk) and were mainly a one or two words responses (approximately 50\%). The teacher often asked questions expecting either true or false or simply Yes or No. The teacher rarely asked questions that would create longer responses but when it happened, students' responses tended to be grammatically incorrect

\subsection{Interactional Moves Used by Teachers in Saudi Arabia to Elicit Students' Participation}

The teacher used a variety of techniques to elicit students' participation in each class. Questions were the most common in each class. The teacher directly asked students to answer. The questions were either from the textbook or general questions. Almost $40 \%$ of the questions were expecting a one or two word answers. Most of the questions the teacher asked were either Yes or No questions or true or false questions. It was noted that all the questions the teacher asked were display questions and there was not a single instance of a referential question. The absence of referential questions is quite interesting as it is believed that these particular kind of questions elicit classroom interaction [6]. The teacher also used general questions quite often. These questions were addressed to the whole class and similar to Shomoossi's findings students replied silently or as a group [6].

Another point that should be taken into consideration is the fact that in many instances the teacher asked questions but did not give students the chance to answer. The teacher would immediately provide the answer.

\subsection{Corrective Feedback Techniques Used by Teachers in Saudi Arabia}

Most of the feedback the teacher provided was on content (73\%) rather than on language. The teacher provided feedback on language sparingly. This might have deprived students of the chance to improve their language. Previous studies have found that learners exposed to feedback were more successful in accomplishing classroom activities than learners who were not provided with feedback [16]. The teacher rarely gave positive feedback where he would provide a confirmation of students' responses. There were, however, relatively more instances of corrective feedback where the teacher commented on students' mistakes.

Many techniques were used for feedback. Similar to other studies repetitions and recasts were the most common forms of feedback [12]. In many occasions the teacher would simply repeat students exact words with or without further elaboration (125 repetitions out of 182 feedback instances). Students were probably confused as it was not always clear if the teacher was just repeating their responses to confirm them.

A closer look into students' responses to the different types of feedback shows that even when feedback was provided, students were not given a chance to uptake feedback. As suggested by Lyster and Ranta students' uptake is extremely important as it provides students with the opportunity to utilize teachers' feedback and repair their responses [12].

\section{Conclusion}

In this particular classroom the L1 was used sparingly by both the teacher and students. Even though the teacher managed to use the TL, students did not get the chance to follow the teacher's example. The teacher used a variety of elicitation moves but he was not successful in eliciting students' participation. The teacher used many techniques to provide feedback but he neglected the ultimate goal of feedback which is allowing students to benefit from the feedback he provided. The teacher did not give students a chance to repair their responses.

The findings suggest that the aim in EFL and ESL classes should be enabling students to successfully practice the TL in the classroom rather than avoiding the use of the L1. The L1 as the findings suggest is not the only obstacle to improving students' acquisition of the TL. As suggested by Edstrom L1 could probably be an asset to teaching the TL rather than the enemy [2].

The findings of this study cannot be generalised to all ESL classes in Saudi Arabia as it has only investigated a single class with a limited number of students. However, it is a contribution to the limited research on ESL classes in Saudi Arabia. 


\section{References}

[1] Turnbull, M., \& Arnett, K. (2002) Teachers' uses of the target and first language in second and foreign language classrooms. Annual Review of Applied Linguistics, 22, 204-218.

[2] Edstrom, A. (2006). L1 use in the L2 classroom: One teacher's selfevaluation. The Canadian Modern Language Review, 63.2, 275-292.

[3] White, E. (2009) Investigating use of the first language (L1) in the foreign language (FL) classroom. Unpublished master's thesis, The University of Melbourne, Melbourne, AU.

[4] Varshney, R. \& Rolin-Ianziti, J. (2008) Students' views regarding the use of the first language: An exploratory study in a tertiary context maximizing target language use. The Canadian Modern Language Review, 65.2, 249-273.

[5] Paker, T., \& Karaağaç, Ö. (2015). The use and functions of mother tongue in EFL classes. ProcediaSocial and Behavioral Sciences, 199, 111-119.

[6] Shomoossi, N. (2004) The effect of teachers' questioning behavior on EFL classroom interaction: A classroom research study. Reading Matrix, 4, 2, 96-104.

[7] Kim, S. \& Elder, K. (2005) Language choices and pedagogic functions in the foreign language classroom: a cross-linguistic functional analysis of teacher talk. Language Teaching Research, 9, 4, 355-380.

[8] Crichton, H. (2009)' Value added' modern language teaching in the classroom: An investigation into how teachers' use of classroom target language can aid pupils' communication skills. Language Learning Journal, 37.1, 19-39.

[9] Brulhart, K. (1986) Foreigner talk in ESL classroom: interactional adjustment to adult students at two language proficiency levels. TESL. Canada Journal, 1, 29-42.

[10] Alsubaie, S. (2015) An analysis of classroom discourse: Elicitation Techniques in EFL Classrooms. International Journal of English Language Teaching, 3, 8, 29-39.

[11] Long, M. H., Inagaki, S. \& Ortega, L. (1998) The role of negative feedback in SLA: Models and recasts in Japanese and Spanish. The Modern Language Journal, 82, 357-371.

[12] Lyster, R., \& Ranta, L. (1997) Foreigner talk in ESL classroom: interactional adjustment to adult students at two language proficiency levels. TESL Canada Journal, 1, 29-42.

[13] Spada, N., \& Frohlich, M. (1995). COLT Observation Scheme. Sydney: National Centre for English Language Teaching and Research, Macquarie University.

[14] Kirgoz, Y., \& Agcam, R. (2015). Teachers' perceptions on corrective feedback in Turkish primary schools. ProcediaSocial and Behavioral Sciences, 192, 574-581

[15] Lyster, R. \& Saito, K. (2010) Oral feedback in classroom SLA: A meta-analysis. Studies in Second Language Acquisition, 32, 256-302.

[16] Ammar, A. \& Spada, N. (2006) One size fits all?: prompts, recasts and L2 learning. Studies in Second Language Acquisition, 28, 543-574.

[17] Syed, Z. (2003) TESOL in the Gulf: The sociocultural context of English language teaching in the Gulf. TESOL Quartrely, $37,2,337-341$. 